Original Research

\title{
Exploring Carbon Neutrality in Power Industry Based on Electric Carbon Productivity: a Multi-Dimensional Decomposition from the Perspective of Production and Consumption
}

\author{
Peiyan $\mathrm{Li}^{1 *}$, Wei Sun${ }^{1}$, Ziyun Cheng², Wenting Wang ${ }^{3}$, Yujun $\mathrm{He}^{4}$
}

${ }^{1}$ School of Economics and Management, North China Electric Power University, Baoding 071003, China ${ }^{2}$ Division of Development, Gansu Electric Power Corporation, State Grid (Research Institute of Economy and Technology), Lanzhou 730050, China

${ }^{3}$ School of Electrical Engineering and Information Engineering, Lanzhou University of Technology, Lanzhou 730050, China

${ }^{4}$ School of Electrical and Electronic Engineering, North China Electric Power University, Baoding 071003, China

Received: 30 August 2021

Accepted: 6 November 2021

\begin{abstract}
Achieving carbon-neutrality 2060 target is a solemn commitment made by China to the world. In the process of advancing carbon neutrality goals, power industry is an important starting point for addressing climate change. This study employs China's electric carbon productivity (ECP) to efficiently integrate economy and environment to explore carbon neutrality in power industry. Based on the electricity, economy, and population-related data of 30 provinces and municipalities in China from 2007 to 2017, the LMDI method is used to decompose ECP on the power production and consumption side, while considering regional and industrial dimensions. Furthermore, it is divided into six drivers respectively. The results show that: 1) From the production perspective, the regional ECP and reciprocal of standard coal consumption for power supply are the dominating drivers to improve China's ECP. 2) From the consumption perspective, the per capita GDP and reciprocal of provincial industrial electricity consumption intensity are primary drivers in the rise of ECP. 3) The regional decomposition indicates that electricity utilization efficiency and economic development mode are the main reasons why Xinjiang's ECP level is lower than that of Guangdong and Jiangsu. Finally, some conclusions that may be helpful to the government and enterprises are drawn.
\end{abstract}

Keywords: electric carbon productivity, production and consumption-based decomposition, power industry, carbon neutrality, Logarithmic Mean Divisia Index (LMDI) decomposition

*e-mail: 953132937@qq.com 


\section{Introduction}

The world's durative electrification makes the power industry the central role in global energy system [1]. This is the case in China. Electricity, the primary energy, is the backbone for China's economy, since the continuous electricity production and supply is required to match the rapid continuous economic development. In 2020, the elasticity coefficient of electricity consumption reached 1.35 , which means the resilient and vigorous gross domestic product (GDP) with the growth rate of $2.3 \%$ is supported by the total electricity consumption with the growth rate of 3.1\% [2]. Still dominated by fossil fuel-based power plants, China's power industry accounts for $30.03 \%$ of the national total carbon dioxide $\left(\mathrm{CO}_{2}\right)$ emissions in 2019 [3]. Apparently, the power industry plays a vital role in realizing the goal of peaking the carbon emissions around 2030 and reaching carbon neutrality by 2060 , proposed in the $75^{\text {th }}$ session of the UN General Assembly in 2020. The concept of carbon neutrality is based on the theory of net-zero emissions, which means that the amount of $\mathrm{CO}_{2}$ emission and absorption in the system are equal [4]. The kernel of applying carbon neutrality to the power industry is carbon abatement. Under such severe situation, more attention has been drawn by the central and local governments to balance the steady economic development and the $\mathrm{CO}_{2}$ emissions from the power industry [5-6]. Therefore, carbon productivity enhancement would be the fundamental means to achieve carbon neutrality.

Carbon productivity, coined by Kaya and Yobobori (1999), is defined as the amount of economic output per $\mathrm{CO}_{2}$ emission [7]. It is an integrated indicator to evaluate the coordination of emission reduction and the sustainable steady economic growth, which can also evaluate certain country's or industry's low-carbon development level [8-9]. By applying carbon productivity to the power industry, electric carbon productivity is very appropriate to assess the contribution to the national emission reduction [1011]. Meanwhile, the ECP improvement is a pivotal measure to decrease the cost of power industry emission reduction and realize the coordination of maintaining acceptable economic development supported by the power industry.

Recently, a number of scholars have paid more and more attention to the carbon productivity. The study of carbon productivity has devoted to expanding the research of coordination between economy and environment from different aspects. Certain relevant references mainly focused the trend analysis, such as the growth trend, the convergence trend, the spillover effect, etc. which involves national, industrial or regional aspect. He and Su (2009) [12] mainly made a theoretical analysis of the annual growth rate of carbon productivity and the key factors of enhancing carbon productivity in order to assess the effort to echo the climate change. Yu et al. (2017) [13] provided a novel index to measure the carbon productivity growth for the stated- and non-state-owned power plants, which could assess the heterogeneities and technological progress on the productivity. Yu et al. (2017) [14] proposed a new method to quantify the carbon productivity for regional transport industry and explored the dynamic change across different geographic regions. Bai et al. (2019) [15] applied the log t regression method and the club convergence theory to test the carbon productivity convergence trend for eighty-eight countries and regions for the period of 1975-2013. Ding et al. (2019) [16] combined the cross efficiency and Malmquist productivity index to explore the time effect of energy and economy on the provincial productivity, and investigate the dynamic change of carbon efficiency for China's 30 provinces. Hu et al. (2020) [17] investigated the spatial correlation between different regions' carbon productivity to find out the threshold of the environmental regulation on the carbon productivity based on the spatial spillover effect. Pan et al. (2011) [18] employed Theil index, decoupling technique and clustering theory to analyze the provincial difference of carbon productivity, and provided the targeted measures for abating carbon emission.

A vast body of research work has investigated the driving indicators of carbon productivity or the influential mechanism of certain factor on carbon productivity by entities at national scale or different provincial or industrial scale. There are two main research branches. One branch focused on the driving factors investigation of carbon productivity from nation-, industrial-, or provincial aspect, showing as follows. Hu and Liu (2016) [19] applied the LMDI decomposition technique to explore the potential drivers of machinery and equipment net capital stock, construction work done and other representative indicators on carbon productivity in Australian construction industry. Long et al. (2016) [20] employed the Moran's I index and spatial panel data model to explore the influence of space-time characteristics and main drivers such as industrial energy efficiency on industrial carbon productivity from 2005 to 2012 for 30 provinces. Li and Wang (2019) [21] applied the spatial econometric model and the STIRPAT decomposition technique to assess the impact of socioeconomic indicator on the country's carbon productivity. Yang et al. (2021) [22] applied the production-theoretical decomposition technique to investigate the main influencing factors such as industrial added value, capital and labor at the provincial and sectoral levels and the regional disparities. The other research branch focuses on the influential mechanism of one factor or several factors, such as: foreign trade, technology, technological progress, etc, showing as follows. Zhang et al. (2018) [23] concluded that China's carbon productivity will be boosted mainly by export-import, especially import. $\mathrm{Du}$ et al. (2019) [24] argued that green technology innovations could only be effective in increasing carbon productivity in high-income economies and encouraged 
worldwide green technology corporation. Pan et al. (2020) [25] found that outward foreign direct investment promoted total factor carbon productivity by enhancing regional technology capabilities. Long et al. (2020) [26] concluded that local Foreign Direct Investment could boosted local carbon productivity due to structural effect, while surroundings areas Foreign Direct Investment reduced local carbon productivity. Fan et al. (2021) [27] came to a conclusion that the progress of capital-embodied technology and neutral technology indirectly affected carbon productivity (CP) through the progress of energy technology and carbon technology respectively, which were beneficial to improve CP.

Given the aforementioned, though the power industry plays a crucial role in national carbon neutrality goal and the future sustainable development of power industry, the researches on carbon productivity of electric power industry are limited. Especially to the author's knowledge, the study that investigates the drivers from the production and consumption aspects simultaneously is scarce. The production side and consumption side are linked by electric transmission network, which is inseparable from electricity supply. Therefore, it is necessary to analyze the effect of possible productionside driving factors and the consumption-side factors on electric carbon productivity.

In this paper, we attempt to investigate the time series characteristics of ECP and decompose the ECP from multi-dimensions which involve provincial-, industrial- aspects and production-side, consumptionside to explore the comprehensive influential factors. The contributions of our work lie in three aspects. First, the research data were extended to 30 provinces as well as the industrial scale. Second, the time series characteristics of influential factors' contribution rate on ECP were explored in our work. Third, from the multi-dimensions involving production-, consumption -side, and provincial-, industrial perspective, an indepth comprehensive investigation of drivers of ECP was carried out through using the LMDI technique, so as to provide theoretical support for carbon neutrality in power industry.

The paper is organized as follows. The definition of electric carbon productivity and the LMDI decomposition method based on production and consumption are given in Section 2. Section 3 describes the data part in detail. And then, Section 4 elaborates the decomposition results and discusses the empirical results. The conclusions of this paper and some policy recommendations for the government and enterprises are drawn in Section 5.

\section{Methodology and Data Sources}

\section{Concept of Electric Carbon Productivity}

According to the original concept of carbon productivity, advanced by Kaya and Yobobori [7], ECP is defined as the ration of the economic output to the amount of $\mathrm{CO}_{2}$ emissions from power industry due to the electricity generation or terminal consumption, shown as Eq. (1).

$$
P=G / C
$$

where $G$ represents the economic output; $C$ represents the amount of $\mathrm{CO}_{2}$ emissions from power industry, which can be calculated through Eq. (2).

$$
C=T \times S \times 2.6308 \text { ton } \mathrm{CO}_{2} / \text { tce }
$$

where $T$ is the amount of thermal power generation, $S$ is the standard coal consumption per unit power generation, 2.6306 ton $\mathrm{CO}_{2} /$ tce is the $\mathrm{CO}_{2}$ emission coefficient per unit standard coal, recommended by the National Development and Reform Commission (NDRC) Energy Research Institute (ERI) [28].

\section{Production-Side Based Decomposition for ECP}

LMDI, provided by Ang B.W. in 1998, is a commonly used decomposition technique, which has been used to investigate the drivers on certain parameter with perfect decomposition character and no decomposition residuals [29]. In our work, the LMDI decomposition technique is adopted to analyze drivers of ECP change from production-side and consumption-side, and with considering provincial and industrial dimensions. The production-side based and consumption-side decomposition for ECP are described in detail in the next sections.

Based on LMDI decomposition technique, ECP is decomposed as Eq. (3) to analyze drivers of ECP change from power generation perspective, shown as follows.

$P=\frac{G}{C}=\frac{\sum_{i=1}^{n} G_{i}}{C}=\frac{\sum_{i=1}^{n} \frac{G_{i}}{E C E_{i}} \times \frac{E C E_{i}}{T H P G_{i}} \times \frac{T H P G_{i}}{T P G_{i}} \times \frac{T P G_{i}}{T P S_{i}} \times \frac{T P S_{i}}{S C C_{i}} \times \frac{S C C_{i}}{N S C_{i}} \times N S C_{i}}{C}$
$=\sum_{i=1}^{n} P_{i} \times T C I_{i} \times P G S_{i} \times P U R_{i} \times P S C_{i} \times R S C_{i} \times C E F$

Where $G_{i}$ is the GDP of province $i(i=1,2 \ldots \ldots, n)$, $E C E_{i}$ represents $\mathrm{CO}_{2}$ emissions from power industry of province $i, T H P G_{i}$ represents thermal power generation of province $i, T P G_{i}$ represents total power generation of province $i, T P S_{i}$ represents total power supply of province $i, S C C_{i}$ represents total standard coal consumption of province $i$, and $N S C_{i}$ represents national standard coal consumption. Moreover, $P_{i}$ is the ECP of province $i, T C I_{i}$ denotes the $\mathrm{CO}_{2}$ emissions per unit thermal power generation, i.e. the $\mathrm{CO}_{2}$ emission intensity of power generation, $P G S_{i}$ represents 
the proportion of thermal power generation in total power generation of province $i, P U R_{i}$ denotes the ration of power generation to power supply of province $i$, $P S C_{i}$ is the reciprocal of standard coal consumption rate per unit power supply province $i, R S C_{i}$ denotes the proportion of standard coal consumption in province $i$ to national standard coal consumption, $C E F$ is the reciprocal to carbon emission factor of national standard coal.

\section{Consumption-Side Based Decomposition for ECP}

From the consumption side, the ECP could be decomposed as Eq. (4)

$P=\frac{G}{C}=\frac{\sum_{i=1}^{n} \sum_{j=1}^{m} G_{i j}}{C}=\frac{\sum_{i=1}^{n} \sum_{j=1}^{m} \frac{G_{i j}}{E_{i j}} \times \frac{E_{i j}}{E_{i}} \times \frac{E_{i}}{G_{i}} \times \frac{G_{i}}{P O P} \times \frac{P O P}{P O P} \times P O P}{C}$ $=\sum_{i=1}^{n} \sum_{j=1}^{m} R E C I_{i j} \times I E C_{i j} \times E C I_{i} \times P C G_{i} \times P R_{i} \times P C$

where $G_{i j}$ is the GDP added value of industrial sector $j$ in province $i, E_{i j}$ is the power consumption of industrial sector $j$ in province $i, E_{i}$ indicates the total power consumption of province $i, P O P_{i}$ denotes the population of province $i, P O P$ represents the national population. In addition, $R E C I_{i j}$ is the reciprocal of industrial electricity consumption intensity of province $i, I E C_{i j}$ is the proportion of industrial power consumption to provincial total power consumption, $E C I_{i}$ is the electricity consumption intensity of province $i, P C G_{i}$ denotes per capital GDP of province $i, P R_{i}$ represents the ration of provincial population to the total amount, i.e. the population scale of province $i, P C$ is the ratio of total population to total $\mathrm{CO}_{2}$ emissions from power industry, i.e. the reciprocal of $\mathrm{CO}_{2}$ emissions per capita.

\section{Additive Decomposition Method}

\section{Analysis of Production Side}

In order to analyze the effect of drivers on ECP, the addictive decomposition technique of LMDI [29] is adopted in our work.

First, Eq. (3) is differentiated about time $t$ to yield Eq. (5).

$$
\begin{aligned}
\frac{d P_{t}}{d t}= & \frac{d P_{i t}}{d t} \cdot T C I_{i t} \cdot P G S_{i t} \cdot P U R_{i t} \cdot P S C_{i t} \cdot R S C_{i t} \cdot C E F_{t} \\
& +\frac{d T C I_{i t}}{d t} \cdot P_{i t} \cdot P G S_{i t} \cdot P U R_{i t} \cdot P S C_{i t} \cdot R S C_{i t} \cdot C E F_{t} \\
& +\frac{d P G S_{i t}}{d t} \cdot P_{i t} \cdot T C I_{i t} \cdot P U R_{i t} \cdot P S C_{i t} \cdot R S C_{i t} \cdot C E F_{t} \\
& +\frac{d P U R_{i t}}{d t} \cdot P_{i t} \cdot T C I_{i t} \cdot P G S_{i t} \cdot P S C_{i t} \cdot R S C_{i t} \cdot C E F_{t} \\
& +\frac{d P S C_{i t}}{d t} \cdot P_{i t} \cdot T C I_{i t} \cdot P G S_{i t} \cdot P U R_{i t} \cdot R S C_{i t} \cdot C E F_{t} \\
& +\frac{d R S C_{i t}}{d t} \cdot P_{i t} \cdot T C I_{i t} \cdot P G S_{i t} \cdot P U R_{i t} \cdot P S C_{i t} \cdot C E F_{t} \\
& +\frac{d C E F_{t}}{d t} \cdot P_{i t} \cdot T C I_{i t} \cdot P G S_{i t} \cdot P U R_{i t} \cdot P S C_{i t} \cdot R S C_{i t}
\end{aligned}
$$

Through calculating the definite integral of Eq. (5) over the time interval $\left[t_{1}, t_{2}\right]$, where $t_{1}$ and $t_{2}$ are the benchmark year and the target year respectively $\left(t_{2}>t_{1}\right)$, Eq. (6) can be obtained as follows.

$$
\begin{aligned}
\Delta P & =P_{t_{2}}-P_{t_{1}} \\
= & \int_{t_{1}}^{t_{2}}\left(\frac{d R E C I_{i j t}}{d t} \cdot I E C_{i j t} \cdot E C I_{i t} \cdot P C G_{i t} \cdot P R_{i t} \cdot P C_{t}\right) \\
& +\int_{t_{1}}^{t_{2}}\left(\frac{d I E C_{i j t}}{d t} \cdot R E C I_{i j t} \cdot E C I_{i t} \cdot P C G_{i t} \cdot P R_{i t} \cdot P C_{t}\right) \\
& +\int_{t_{1}}^{t_{2}}\left(\frac{d E C I_{i t}}{d t} \cdot R E C I_{i j t} \cdot I E C_{i j t} \cdot P C G_{i t} \cdot P R_{i t} \cdot P C_{t}\right) \\
& +\int_{t_{1}}^{t_{2}}\left(\frac{d P C G_{i t}}{d t} \cdot R E C I_{i j t} \cdot I E C_{i j t} \cdot E C I_{i t} \cdot P R_{i t} \cdot P C_{t}\right) \\
& +\int_{t_{1}}^{t_{2}}\left(\frac{d P R_{i t}}{d t} \cdot R E C I_{i j t} \cdot I E C_{i j t} \cdot E C I_{i t} \cdot P C G_{i t} \cdot P C_{t}\right) \\
& +\int_{t_{1}}^{t_{2}}\left(\frac{d P C_{t}}{d t} \cdot R E C I_{i j t} \cdot I E C_{i j t} \cdot E C I_{i t} \cdot P C G_{i t} \cdot P R_{i t}\right)
\end{aligned}
$$

Eq. (6) is difficult to calculate the weight function including the time term. Consequently, Vartia [30] and Sato [31] introduced refinements of the weights to eliminate the influence of $t$. Furthermore, Vartia defined weight function $L(x, y)$, which denotes the 'logarithmic average' with Vartia Indices I and II [32].

$$
L(x, y)= \begin{cases}\frac{x-y}{\ln x-\ln y} & x \neq y \\ x & x=y\end{cases}
$$

In additive decomposition, the change in ECP for the period of $t_{1}$ to $t_{2}$ can be decomposed into seven factors: regional effect $\Delta P_{P i}, \mathrm{CO}_{2}$ emission intensity of thermal power generation effect $\Delta P_{T C I i}$, power generation structure effect $\Delta P_{P G S i}$, import-export effect $\Delta P_{\text {PURi }}$, standard coal consumption for power supply effect $\Delta P_{P S C i}$, standard coal structure effect $\Delta P_{R S C i}$, emission-factor effect $\Delta P_{C E F}$, shown as Eq. (8). 


$$
\begin{gathered}
\Delta P=P_{t_{2}}-P_{t_{1}}=\Delta P_{P_{i}}+\Delta P_{T I_{i}}+\Delta P_{P G S_{i}}+\Delta P_{P U R_{i}} \\
+\Delta P_{P S C_{i}}+\Delta P_{R S C_{i}}+\Delta P_{C E F}
\end{gathered}
$$

Therefore, the contribution of each effect on ECP could be obtained through Eqs (9)-(15), respectively.

$$
\begin{aligned}
& \Delta P_{P_{i}}=\sum_{i} f\left(\frac{G_{i}^{t_{2}}}{C^{t_{2}}}, \frac{G_{i}^{t_{1}}}{C^{t_{1}}}\right) \cdot \ln \left(\frac{P_{i}^{t_{2}}}{P_{i}^{t_{1}}}\right)
\end{aligned}
$$

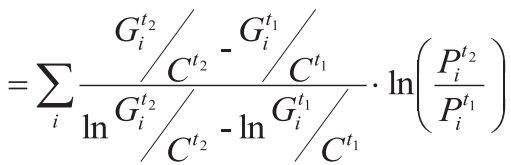

$$
\begin{aligned}
& \Delta P_{T C I_{i}}=\sum_{i} f\left(\frac{G_{i}^{t_{2}}}{C^{t_{2}}}, \frac{G_{i}^{t_{1}}}{C^{t_{1}}}\right) \cdot \ln \left(\frac{T C I_{i}^{t_{2}}}{T C I_{i}^{t_{1}}}\right) \\
& =\sum_{i} \frac{G_{i}^{t_{2}} / C^{t_{2}-} G_{i}^{t_{1}} / C^{t_{1}}}{\ln G_{i}^{t_{2}} / C^{t_{2}}-\ln G_{i}^{t_{1}} / C^{t_{1}}} \cdot \ln \left(\frac{T C I_{i}^{t_{2}}}{T C I_{i}^{t_{1}}}\right) \\
& \Delta P_{P G S_{i}}=\sum_{i} f\left(\frac{G_{i}^{t_{2}}}{C^{t_{2}}}, \frac{G_{i}^{t_{1}}}{C^{t_{1}}}\right) \cdot \ln \left(\frac{P G S_{i}^{t_{2}}}{P G S_{i}^{t_{1}}}\right) \\
& =\sum_{i} \frac{G_{i}^{t_{2}} / C^{t_{2}}-G_{i}^{t_{1}} / C^{t_{1}}}{\ln G_{i}^{t_{2}} / C^{t_{2}}-\ln G_{i}^{t_{1}} / C^{t_{1}}} \cdot \ln \left(\frac{P G S_{i}^{t_{2}}}{P G S_{i}^{t_{1}}}\right) \\
& \Delta P_{P U R_{i}}=\sum_{i} f\left(\frac{G_{i}^{t_{2}}}{C^{t_{2}}}, \frac{G_{i}^{t_{1}}}{C^{t_{1}}}\right) \cdot \ln \left(\frac{P U R_{i}^{t_{2}}}{P U R_{i}^{t_{1}}}\right) \\
& =\sum_{i} \frac{G_{i}^{t_{2}} / C^{t_{2}}-G_{i}^{t_{1}} / C^{t_{1}}}{\ln G_{i}^{t_{2}} / C^{t_{2}}-\ln G_{i}^{t_{1}} / C^{t_{1}}} \cdot \ln \left(\frac{P U R_{i}^{t_{2}}}{P U R_{i}^{t_{1}}}\right) \\
& \Delta P_{P S C_{i}}=\sum_{i} f\left(\frac{G_{i}^{t_{2}}}{C^{t_{2}}}, \frac{G_{i}^{t_{1}}}{C^{t_{1}}}\right) \cdot \ln \left(\frac{P S C_{i}^{t_{2}}}{P S C_{i}^{t_{1}}}\right) \\
& =\sum_{i} \frac{G_{i}^{t_{2}} / C^{t_{2}}-G_{i}^{t_{1}} / C^{t_{1}}}{\ln G_{i}^{t_{2}} / C^{t_{2}}-\ln G_{i}^{t_{1}} / C^{t_{1}}} \cdot \ln \left(\frac{P S C_{i}^{t_{2}}}{P S C_{i}^{t_{1}}}\right) \\
& \Delta P_{R S C_{i}}=\sum_{i} f\left(\frac{G_{i}^{t_{2}}}{C^{t_{2}}}, \frac{G_{i}^{t_{1}}}{C^{t_{1}}}\right) \cdot \ln \left(\frac{R S C_{i}^{t_{2}}}{R S C_{i}^{t_{1}}}\right) \\
& =\sum_{i} \frac{G_{i}^{t_{2}} / C^{t_{2}}-G_{i}^{t_{1}} / C^{t_{1}}}{\ln G_{i}^{t_{2}} / C^{t_{2}}-\ln G_{i}^{t_{1}} / C^{t_{1}}} \cdot \ln \left(\frac{R S C_{i}^{t_{2}}}{R S C_{i}^{t_{1}}}\right) \\
& \Delta P_{C E F}=\sum_{i} f\left(\frac{G_{i}^{t_{2}}}{C^{t_{2}}}, \frac{G_{i}^{t_{1}}}{C^{t_{1}}}\right) \cdot \ln \left(\frac{C E F^{t_{2}}}{C E F^{t_{1}}}\right) \\
& =\sum_{i} \frac{G_{i}^{t_{2}} / C^{t_{2}}-G_{i}^{t_{1}} / C^{t_{1}}}{\ln ^{t_{i}} / C^{t_{2}}-\ln G_{i}^{t_{1}} / C^{t_{1}}} \cdot \ln \left(\frac{C E F^{t_{2}}}{C E F^{t_{1}}}\right)
\end{aligned}
$$

\section{Analysis of Consumption Side}

Based on Eq. (4), the change of ECP for the same research period can be decomposed from the consumption side, shown as Eq. (16).

$$
\begin{gathered}
\Delta P=P_{t_{2}}-P_{t_{1}}=\Delta P_{R E C I_{i j}}+\Delta P_{I E C_{i j}}+\Delta P_{E C I_{i}} \\
+\Delta P_{P C G_{i}}+\Delta P_{P R_{i}}+\Delta P_{P C}
\end{gathered}
$$

where $\Delta P_{R E C I i j}$ denotes the provincial industrial electricity intensity effect, $\Delta P_{I E C i j}$ denotes the electricity consumption structure effect of provincial industry, $\Delta P_{E C l i}$ denotes the provincial electricity consumption intensity effect, $\triangle P_{P C G i}$ denotes the provincial per capita GDP effect, $\Delta P_{P R i}$ denotes the population scale effect, $\triangle P_{P C}$ denotes the $\mathrm{CO}_{2}$ emissions per capita effect. The terms in Eq. (6) can be calculated as Eqs. (17) -(22), respectively.

$$
\begin{aligned}
& \Delta P_{R E C I_{i j}}=\sum_{i} \sum_{j} f\left(\frac{G_{i j}^{t_{2}}}{C^{t_{2}}}, \frac{G_{i j}^{t_{1}}}{C^{t_{1}}}\right) \cdot \ln \left(\frac{R E C I_{i j}^{t_{2}}}{R E C I_{i j}^{t_{i}}}\right) \\
& =\sum_{i} \sum_{j} \frac{G_{i j}^{t_{2}} / C^{t_{2}}-G_{i j}^{t_{1}} / C^{t_{1}}}{\ln G_{i j}^{t_{i j}} / C^{t_{2}}-\ln G_{i j}^{t_{1}} / C^{t_{1}}} \cdot \ln \left(\frac{R E C I_{i j}^{t_{2}}}{R E C I_{i j}^{t_{i}}}\right) \\
& \Delta P_{I E C_{i j}}=\sum_{i} \sum_{j} f\left(\frac{G_{i j}^{t_{2}}}{C^{t_{2}}}, \frac{G_{i j}^{t_{1}}}{C^{t_{1}}}\right) \cdot \ln \left(\frac{I E C_{i j}^{t_{2}}}{I E C_{i j}^{t_{j}}}\right)
\end{aligned}
$$

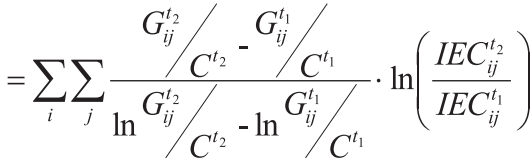

$$
\begin{aligned}
& \Delta P_{E C I_{i}}=\sum_{i} \sum_{j} f\left(\frac{G_{i j}^{t_{2}}}{C^{t_{2}}}, \frac{G_{i j}^{t_{1}}}{C^{t_{1}}}\right) \cdot \ln \left(\frac{E C I_{i}^{t_{2}}}{E C I_{i}^{t_{1}}}\right) \\
& =\sum_{i} \sum_{j} \frac{G_{i j}^{t_{2}} / C^{t_{2}}-G_{i j}^{t_{1}} / C^{t_{1}}}{\ln _{i j}^{t_{i j}} / C^{t_{2}}-\ln G_{i j}^{t_{1}} / C^{t_{1}}} \cdot \ln \left(\frac{E C I_{i}^{t_{2}}}{E C I_{i}^{t_{1}}}\right) \\
& \Delta P_{P C G_{i}}=\sum_{i} \sum_{j} f\left(\frac{G_{i j}^{t_{2}}}{C^{t_{2}}}, \frac{G_{i j}^{t_{1}}}{C^{t_{1}}}\right) \cdot \ln \left(\frac{P C G_{i}^{t_{2}}}{P C G_{i}^{t_{1}}}\right)
\end{aligned}
$$

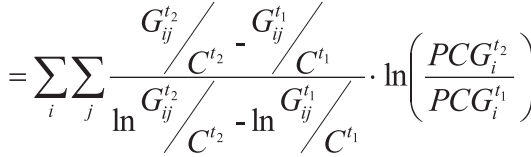

$$
\begin{aligned}
& \Delta P_{P R_{i}}=\sum_{i} \sum_{j} f\left(\frac{G_{i j}^{t_{2}}}{C^{t_{2}}}, \frac{G_{i j}^{t_{1}}}{C^{t_{1}}}\right) \cdot \ln \left(\frac{P R_{i}^{t_{2}}}{P R_{i}^{t_{1}}}\right) \\
& =\sum_{i} \sum_{j} \frac{G_{i j}^{t_{2}} / C^{t_{2}}-G_{i j}^{t_{1}} / C^{t_{1}}}{G_{i j}^{t_{2}} / C^{t_{2}}-\ln G_{i j}^{t_{i j}} / C^{t_{1}}} \cdot \ln \left(\frac{P R_{i}^{t_{2}}}{P R_{i}^{t_{1}}}\right)
\end{aligned}
$$




$$
\begin{aligned}
& \Delta P_{P C}=\sum_{i} \sum_{j} f\left(\frac{G_{i j}^{t_{2}}}{C^{t_{2}}}, \frac{G_{i j}^{t_{1}}}{C^{t_{1}}}\right) \cdot \ln \left(\frac{P C^{t_{2}}}{P C^{t_{1}}}\right) \\
& =\sum_{i} \sum_{j} \frac{G_{i j}^{t_{2}} / C^{t_{2}}-G_{i j}^{t_{1}} / C^{t_{1}}}{G_{i j}^{t_{2}} / C^{t_{2}}-\ln G_{i j}^{t_{1}} / C^{t_{1}}} \cdot \ln \left(\frac{P C^{t_{2}}}{P C^{t_{1}}}\right)
\end{aligned}
$$

\section{Data Sources}

In this paper, 2007 was chosen as the base year of the research period because China had become the world's largest carbon emitter since 2007. For the research period of 2007-2017, data from 30 provinces (including province-level municipalities $\mathrm{i}=1,2, \ldots, 30$ ) are collected in our work, in that Tibet, Macao, Hong Kong and Taiwan are not considered due to the lack of data availability.

On the production side, provincial $G_{i}(100$ million Yuan) data are collected from National Bureau of Statistics (NBS) and provincial ECE data are calculated by Eq. (2). Provincial THPG (billion $\mathrm{kWh}$ ), TPG (billion $\mathrm{kWh}$ ), the auxiliary power consumption rate (\%) and standard coal consumption of power generation $(\mathrm{g} / \mathrm{kWh})$ data are collected from Chinese Electric Power Yearbook (CEPY) of corresponding year [33]. Provincial TPS (billion $\mathrm{kWh}$ ) data are calculated according to provincial $T H P G_{i}$ and the auxiliary power consumption rate, provincial $S C C_{i}$ (100 tons) and $N S C_{i}$ (100 tons) data are calculated by the standard coal consumption of power generation and provincial $T P G_{i}$. On the consumption side, power consumption was considered from three industrial sectors $(\mathrm{j}=1,2,3)$. According to China Energy Statistical Yearbook of corresponding year (CESY) [34], the primary industry includes agriculture, forestry, animal husbandry, fishing and water conservation. The secondary industry consists of industry and construction. The tertiary industry contains transport, storage, post, wholesale, retail trade and other services. Provincial industrial $G_{i j}$ (100 million Yuan) and population (ten thousand persons) data come from NBS, and $E_{i j}$ (billion $\mathrm{kWh}$ ) data come from CESY.

\section{Results and Discussion}

Fig. 1 plots the provincial ECP (100 million Yuan/ten thousand tonnes) series from 2007-2017. On the one hand, the provincial ECP exhibits a fluctuating increasing trend, and notably, it shows significant improvement. On the other hand, the growth rate of provincial ECP shows remarkable regional differences. Compared with 2007, ECP in Yunnan has increased by $633.66 \%$ in 2017 , the fastest growth among all the provinces. Sichuan and Guizhou increase $431.26 \%$ and

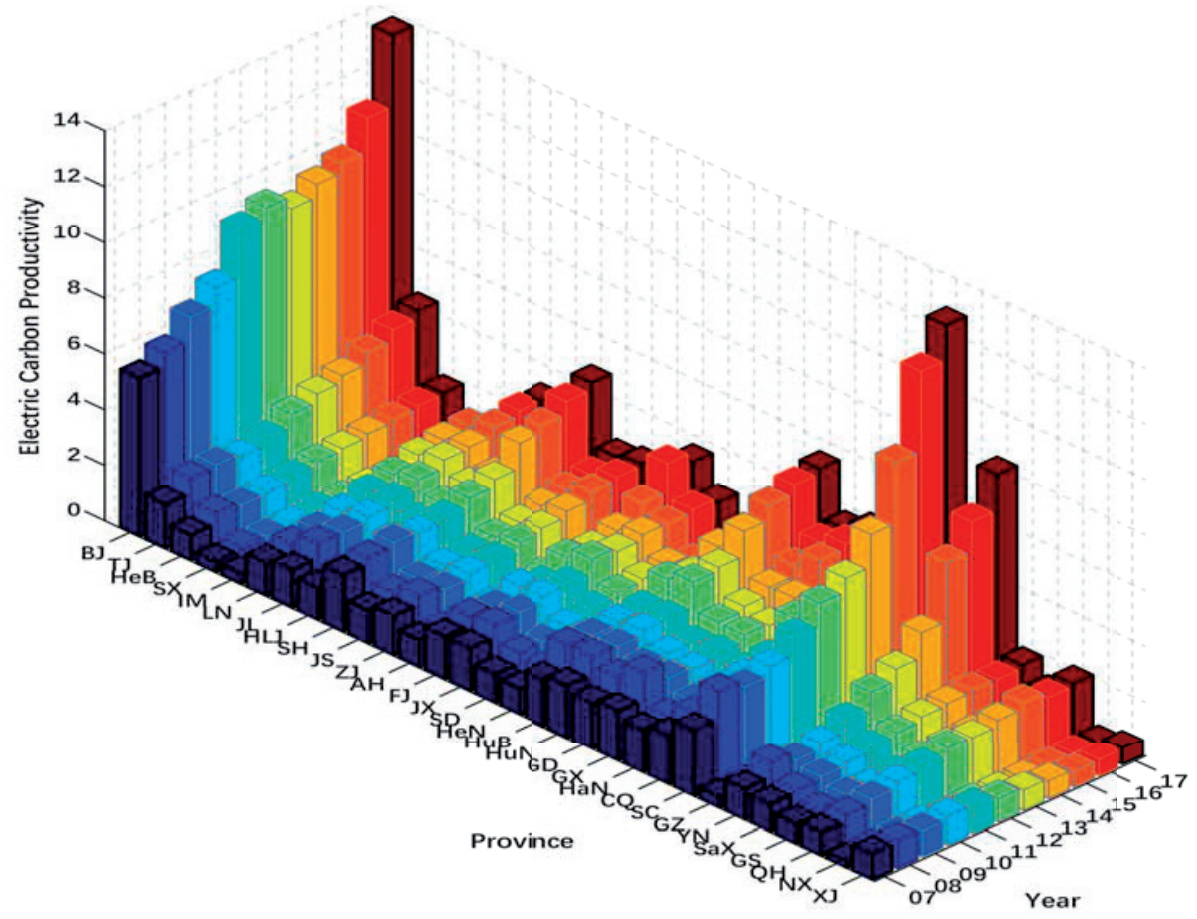

Fig. 1. Provincial ECP series (100 million Yuan/ten thousand tonnes) for the period of 2007-2017.

Note: The abscissa letters represent the abbreviations of 30 provinces, the details are as follows: $\mathrm{BJ}=\mathrm{Beijing}, \mathrm{TJ}=\mathrm{Tianjin}, \mathrm{HeB}=$ Hebei, SX = Shanxi, IM = Inner Mongolia, LN = Liaoning, JL = Jilin, HLJ = Heilongjiang, SH = Shanghai, JS = Jiangsu, ZJ = Zhejiang, $\mathrm{AH}=$ Anhui, $\mathrm{FJ}=$ Fujian, $\mathrm{JX}=$ Jiangxi, $\mathrm{SD}=$ Shandong, $\mathrm{HeN}=$ Henan, HuB $=$ Hubei, HuN $=$ Hunan, GD = Guangdong, GX = Guangxi, HaN = Hainan, CQ = Chongqing, $\mathrm{SC}=$ Sichuan, $\mathrm{GZ}=$ Guizhou, $\mathrm{YN}=$ Yunnan, $\mathrm{SaX}=$ Shaanxi, GS $=\mathrm{Gansu}, \mathrm{QH}=\mathrm{Qinghai}$, $\mathrm{NX}=$ Ningxia, $\mathrm{XJ}=$ Xinjiang. 


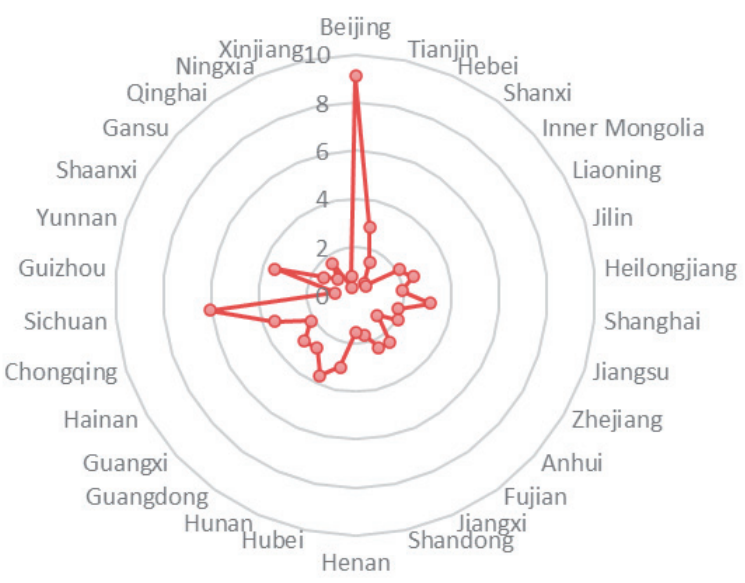

- - The average value of ECP( million Yuan/ten thousand tonnes)from 2007 to 2017 in China

Fig. 2. The average value of ECP in China, 2007-2017.

$251.26 \%$ respectively. ECP in Xinjiang has decreased by $36.03 \%$ in 2017 , which is the only province to show negative growth.

ECP in China shows significant regional differences in time series. For the sake of comparison, Fig. 2 presents the ECP of China's provincial average level from 2007 to 2017. Totally, Beijing ranks the first with the highest ECP level of 9.112 and Ningxia shows the lowest ECP level of 0.327. Specifically, the four provinces with lower ECP average value are Inner Mongolia, Shanxi, Xinjiang and Guizhou, while the two provinces with higher ECP average value are Beijing and Sichuan. Analyzing ECP for each province-level municipalities requires more actual considerations. Further decomposition results need to be explored considering various industry sector and regional factor based on production side and consumption side into account.
Time Decomposition Analysis Based on the Production Side

As shown in Table 1, the contribution rate of each driver of ECP in China is defined as the relative proportion of the change of each driver to the total change in ECP value. $P_{i}$ and $P S C_{i}$ have a positive impact on ECP with the average contribution rates of $168.7 \%$ and $29.2 \%$ to national ECP. PGS $, T_{i}, R S C_{i}$ and $P U R_{i}$ play major roles in the decline of ECP, with the average contribution rates of $-50.3 \%,-22.6 \%,-22 \%$ and $-3.1 \%$, respectively.

Raising $P_{i}$ will distinctly improve the national ECP. $P S C_{i}$ is the reciprocal of the standard coal consumption for power supply. Accordingly, the standard coal consumption for power supply has negative contribution of Chinese ECP. The standard coal consumption for power supply is defined as the average standard coal consumption per one $\mathrm{kWh}$

Table 1. Contribution rates of each driver for Chinese ECP from the production side.

\begin{tabular}{|c|c|c|c|c|c|c|}
\hline Year & $\Delta P_{P-i}$ & $\Delta P_{T C I-i}$ & $\Delta P_{P G S-i}$ & $\Delta P_{P U R-i}$ & $\Delta P_{P S C-i}$ & $\Delta P_{R S C-i}$ \\
\hline $2007-2008$ & 1.626 & -0.191 & -0.529 & -0.001 & 0.198 & -0.104 \\
\hline $2008-2009$ & -0.083 & 0.211 & 0.716 & -0.029 & 0.218 & -0.033 \\
\hline $2009-2010$ & 1.120 & -0.310 & -0.294 & -0.022 & 0.357 & 0.150 \\
\hline $2010-2011$ & 0.793 & -0.153 & 0.351 & -0.031 & 0.187 & -0.147 \\
\hline $2011-2012$ & 2.262 & -0.263 & -0.928 & -0.041 & 0.288 & -0.318 \\
\hline $2012-2013$ & 1.037 & -0.310 & 0.060 & -0.044 & 0.307 & -0.049 \\
\hline $2013-2014$ & 2.442 & -0.239 & -0.974 & -0.037 & 0.262 & -0.453 \\
\hline $2014-2015$ & 3.177 & -0.347 & -1.659 & -0.041 & 0.423 & -0.554 \\
\hline $2015-2016$ & 3.048 & -0.343 & -1.682 & -0.041 & 0.391 & -0.373 \\
\hline $2016-2017$ & 1.451 & -0.319 & -0.086 & -0.020 & 0.293 & -0.320 \\
\hline $2007-2017$ (Average) & 1.687 & -0.226 & -0.503 & -0.031 & 0.292 & -0.220 \\
\hline
\end{tabular}


of power supply in coal-fired power plants, and it is also one of the important assessment indicators for thermal power plants. Cutting-edge clean coal technology can reduce the standard coal consumption of power supply by improving power supply efficiency, such as $700^{\circ} \mathrm{C}$ ultra-supercritical power generation technology [35].

Obviously, $P G S_{i}$ is a driver with the largest contribution rate among the negative factors. According to CESY, the share of clean energy generation (including hydropower, nuclear power, wind power and solar power) increased from $16.66 \%$ in 2007 to $37.82 \%$ in 2017 , while the share of thermal power generation decreased from $83.34 \%$ to $62.18 \%$. However, thermal power generation is still the main source of $\mathrm{CO}_{2}$ emissions in China [36], and China needs to reduce the proportion of thermal power generation to accelerate carbon neutrality. $T C I_{i}$ as a whole has a negative impact, which was actually related to the power generation technology and the fuel structure of generator units [37]. It is effective to boost ECP by improving the technical level and optimizing the fuel consumption structure. To some extent, $R S C_{i}$ reflects the electricity consumption proportion of each province to the national amount. The decomposition results show that coal has maintained a fundamental position in China's energy structure for a long time. Although the proportion of coal in primary energy production decreased from $81.6 \%$ in 2007 to $76.6 \%$ in 2017, coal is still the most important primary energy source. Therefore, in the long run, it is necessary to vigorously develop clean energy to reduce the dependence on coal resources, which may be the first target to achieve carbon neutrality. $P U R_{i}$ shows the least negative contribution to ECP in China. In fact, PURi is related to the auxiliary power consumption rate. Reducing the auxiliary power consumption rate requires optimizing operation technology, improving equipment maintenance and using independent innovation to implement energysaving technological transformation.

Fig. 3 explicitly displays the time series decomposition results of each driver of ECP increments from the production side. In general, ECP has shown annual growth trend since 2007. The policy of "suppressing the small thermal power units with high energy consumption and heavy pollution" was implemented in 2007, which had a significant impact on energy conservation and emission reduction. During the period of the $11^{\text {th }}$ Five-Year Plan, a total of 72.1 million kilowatts of small thermal power units have been shut down. The measure reduced $\mathrm{CO}_{2}$ emissions by 124 million tons per year [38].

ECP has five stages of significant change. From 2007 to 2010, the increment in ECP along the timeline was $0.1814,0.126$, and 0.0944 . China's GDP had been affected by the global financial crisis and its economic performance had declined. In 2008, 2009 and 2010, the GDP growth rates were $9.7 \%, 9.4 \%$ and $10.6 \%$, respectively, which were down from $14.2 \%$ in 2007. Furthermore, the economic crisis had led to a reduction in economic activities and power consumption, thereby reducing electricity $\mathrm{CO}_{2}$ emissions. $\mathrm{CO}_{2}$ emissions in power industry dropped from $2379.34 \mathrm{MT}$ in 2007 to 2303.21MT in 2008, with the growth rate of $-3.20 \%$, which was the lowest value during the research period (Fig. 4). From 2009 to 2010, what restrained ECP was the power generation structure and $\mathrm{CO}_{2}$ emission intensity of thermal power generation. It is due to the weakening of the adjustment measures for high energy-

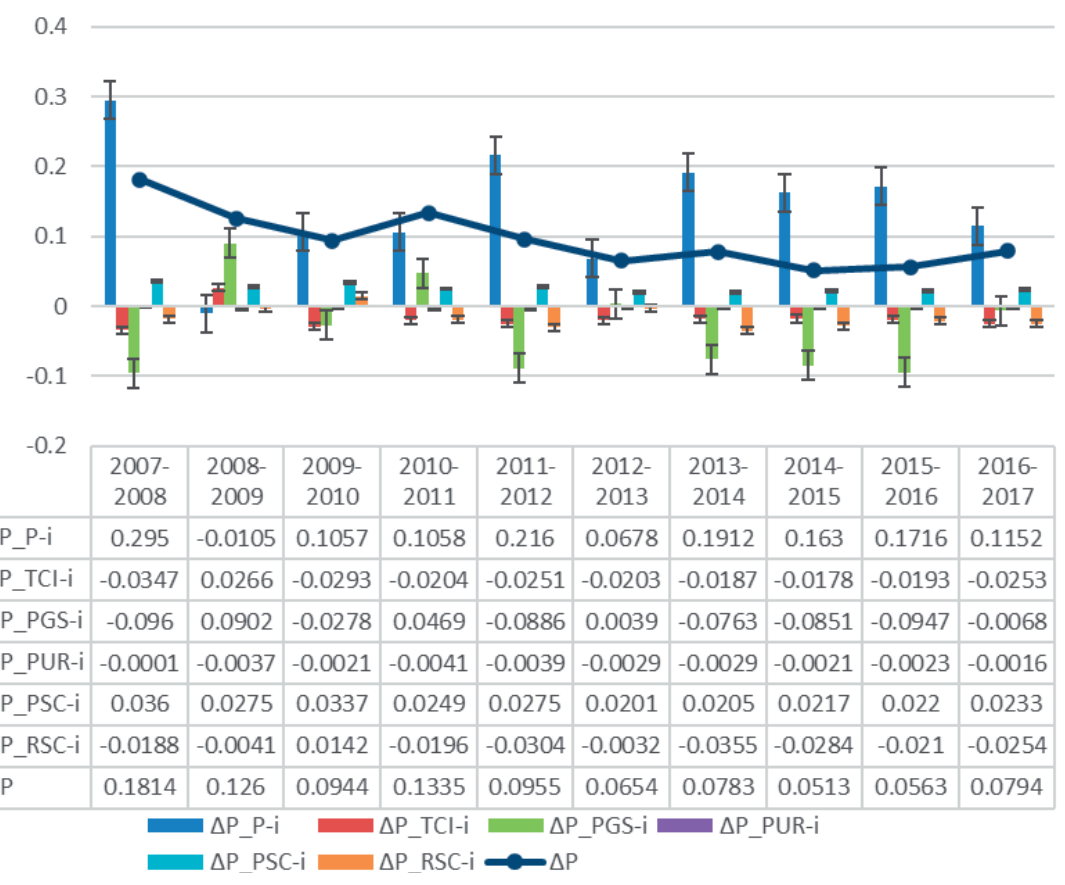

Fig. 3. Effects of drivers for Chinese ECP increment from the production side. 


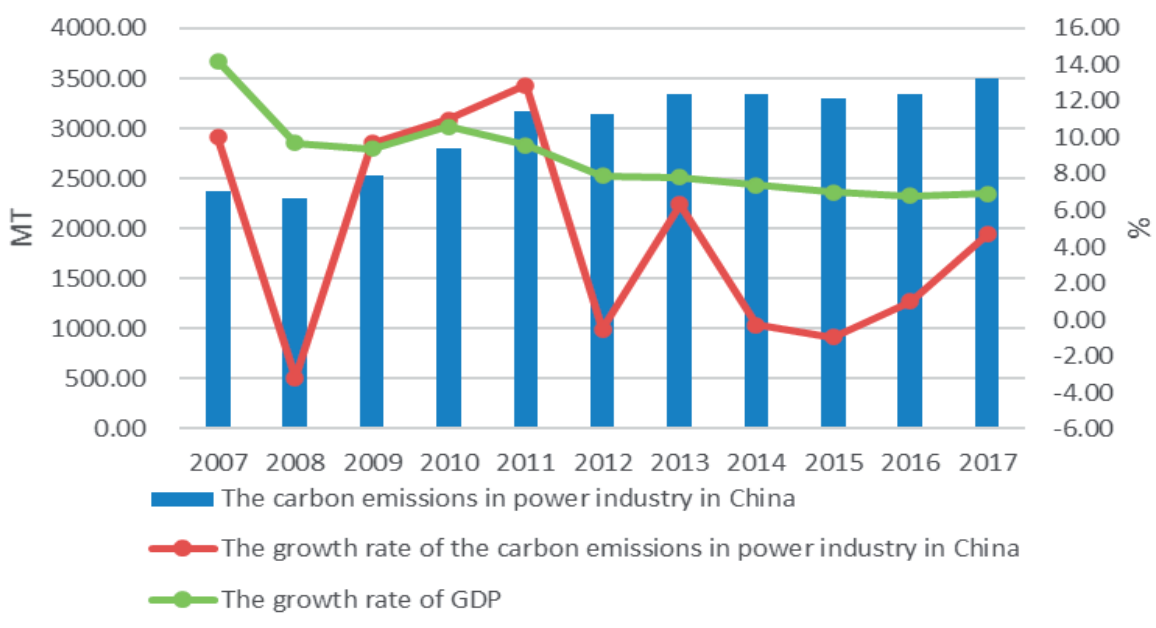

Fig. 4. Chinese electricity $\mathrm{CO}_{2}$ emissions and GDP growth rate, 2007-2017.

intensive industries during this period, which led to a $10.99 \%$ growth rate of electricity $\mathrm{CO}_{2}$ emissions. In 2010-2011, ECP increment reached the second highest value of 0.1335 . China's four trillion USD investment plan in response to the economic crisis had partly stimulated infrastructure construction and heavy industries, such as the emission-intensive power sector, which were slowly recovering from the recession [39]. This led to a rapid increase in power consumption and therefore electricity $\mathrm{CO}_{2}$ emissions increased by $12.87 \%$ in 2011 (Fig. 4), the highest value in the research period. In 2014-2015, the ECP increment was 0.0513 , the lowest value during the research period. It was in line with the fact that local governments focused on economic growth and led to the emergence of energy-intensive projects rebound at the end of the $12^{\text {th }}$ Five-Year Plan period. From 2015 to 2017, the increment of ECP were 0.0563 and 0.0794 along the timeline, showing an upward trend. China's power generation structure has been further optimized. The proportion of clean energy power generation in 2015-2017 was $26.30 \%, 28.15 \%$ and $37.82 \%$, respectively, compared to only $16.67 \%$ in 2007 .

\section{In-Depth Analysis of the Provinces Based on Production Side}

In this part, the decomposition results of ECP are displayed in the form of provinces (Table 2). Regional ECP $(\Delta P p-i)$ shows significant differences. Only the contribution value in Xinjiang is negative. Specifically, the GDP in Xinjiang increased by $208.87 \%$ from 2007 to 2017; $\mathrm{CO}_{2}$ emissions increased by $382.82 \%$ from 2007 to 2017 . It can be seen that the economic growth is an expansive negative decoupling relationship with electricity $\mathrm{CO}_{2}$ emissions. Although the contribution values of Ningxia, Qinghai, Hainan and Inner Mongolia show a positive effect, the values are minor. At the same time, Guangdong, Jiangsu, and Sichuan have the highest contribution values. Guangdong and Jiangsu are more developed regions with strict environmental standards. They need to import electricity from other regions to meet power shortages. The inflow of electricity helps reduce local $\mathrm{CO}_{2}$ emissions based on electricity production. In Sichuan, the improvement of energy efficiency and the substitution of non-fossil fuels have led to a decrease in electricity $\mathrm{CO}_{2}$ emissions, dropped from $43.67 \mathrm{MT}$ in 2007 to $36.74 \mathrm{MT}$ in 2017 , with a growth rate of $-34.10 \%$. It can be inferred that clean energy power generation (including hydropower, solar $\mathrm{PV}$, wind energy, etc) is essential to reduce electricity $\mathrm{CO}_{2}$ emissions based on production side. For standard coal structure effect $\left(\Delta P_{R S C-i}\right)$, the decomposition results also reflect that each provincial energy use proportion is obvious unbalanced due to the different regional resources endowment. The contribution value in Sichuan is the lowest due to abundant water resources. The contribution values in Xinjiang, Anhui, Jiangxi and Shanxi are relatively high, indicating that these four provinces are over-reliant on coal resources. Therefore, in order to improve the ECP level of provinces, in the short term, coal production and utilization should be planned reasonably; in the long term, clean energy sources must be exploited and utilized to realize the transformation of economic development pattern. The regional differences in other parameters are not obvious.

\section{Time Decomposition Analysis Based on the Consumption Side}

Table 3 shows the contribution rates of each driving factor of ECP from the consumption side. It should be noted that the data of $\Delta P_{P C G-i}, \Delta P_{P R-i}$ and $\Delta P_{P C}$ in 2008-2009 are abnormal, so they are deleted when calculating the average value. $\Delta P_{P C G-i}, \Delta P_{R E C I-i j}$ and $\Delta P_{P R-i}$ show positive impacts, with the average contribution rates of $120.34 \%, 64.32 \%$ and $2.18 \%$, respectively. $\Delta P_{P C}, \Delta P_{E C I-i}$ and $\Delta P_{I E C-i j}$ play key roles in 
Table 2. Drivers for Chinese provincial ECP (100 million Yuan*10-3/ten thousand tonnes) from the production side in 2007-2017.

\begin{tabular}{|c|c|c|c|c|c|c|}
\hline Province & $\Delta P_{P-i}$ & $\Delta P_{T C l-i}$ & $\Delta P_{P G S-i}$ & $\Delta P_{P U R-i}$ & $\Delta P_{P S C-i}$ & $\Delta P_{R S C-i}$ \\
\hline Beijing & 52.854 & -20.992 & -1.764 & -3.079 & 24.459 & -13.995 \\
\hline Tianjin & 39.233 & -6.393 & -0.338 & -0.246 & 6.870 & -8.168 \\
\hline Hebei & 53.48 & -10.200 & -11.093 & -0.541 & 10.407 & -13.226 \\
\hline Shanxi & 23.885 & -4.268 & -2.952 & -0.263 & 4.501 & -4.723 \\
\hline Inner Mongolia & 9.600 & -3.503 & -8.489 & -0.252 & 3.736 & 9.513 \\
\hline Liaoning & 40.681 & -9.777 & -17.945 & -0.434 & 10.204 & -20.534 \\
\hline Jilin & 28.233 & -6.095 & -3.004 & -0.353 & 6.390 & -7.629 \\
\hline Heilongjiang & 29.526 & -6.487 & -4.756 & -0.365 & 7.001 & -13.826 \\
\hline Shanghai & 57.822 & -5.811 & -1.137 & -0.134 & 5.728 & -22.594 \\
\hline Jiangsu & 131.040 & -20.656 & -1.994 & -2.048 & 22.81 & 5.596 \\
\hline Zhejiang & 70.135 & -11.187 & -0.849 & -1.027 & 12.497 & -0.653 \\
\hline Anhui & 25.099 & -6.981 & -3.331 & -0.610 & 7.816 & 21.375 \\
\hline Fujian & 56.054 & -3.621 & -22.233 & -1.129 & 4.644 & -2.728 \\
\hline Jiangxi & 16.796 & -5.386 & -0.416 & -0.899 & 6.255 & 16.147 \\
\hline Shandong & 92.030 & -23.963 & -12.741 & -1.189 & 25.511 & 7.699 \\
\hline Henan & 82.794 & -10.893 & -4.074 & -1.419 & 12.681 & -18.261 \\
\hline Hubei & 60.134 & -7.578 & -0.565 & -1.056 & 8.591 & 2.285 \\
\hline Hunan & 70.997 & -9.320 & -7.517 & -0.604 & 10.437 & -13.539 \\
\hline Guangdong & 147.647 & -25.442 & -20.448 & -2.051 & 24.099 & -24.245 \\
\hline Guangxi & 33.655 & -4.792 & -9.318 & -0.309 & 5.256 & -5.058 \\
\hline Hainan & 6.563 & -0.582 & -3.795 & -0.024 & 0.532 & 0.950 \\
\hline Chongqing & 36.624 & -5.013 & -6.064 & -0.811 & 5.516 & -0.630 \\
\hline Sichuan & 127.346 & -10.445 & -106.487 & -3.489 & 12.706 & -65.797 \\
\hline Guizhou & 28.133 & -1.927 & -4.097 & 0.459 & 1.686 & -1.462 \\
\hline Yunnan & 67.863 & -2.197 & -64.381 & 0.416 & 1.886 & -41.010 \\
\hline Shannxi & 26.433 & -3.451 & -5.419 & 0.230 & 3.421 & 12.109 \\
\hline Gansu & 10.419 & -1.609 & -4.847 & -0.159 & 1.759 & -0.403 \\
\hline Qinghai & 4.475 & -0.849 & -0.948 & -0.059 & 0.927 & -0.305 \\
\hline Ningxia & 2.755 & -0.702 & -1.273 & 0.047 & 0.665 & 3.247 \\
\hline Xinjiang & -11.485 & -7.476 & -2.020 & -0.168 & 8.147 & 27.853 \\
\hline
\end{tabular}

the decline in ECP, with the average contribution rates of $-55.30 \%,-28.34 \%$ and $-6.29 \%$, respectively.

$\triangle P_{P C G-i}$ is the most obvious driver in the increment of ECP. GDP per capita can represent the level of economic development of a country. Accordingly, economic development will help boost the ECP. $\triangle P_{R E C I-i j}$ has a notable positive impact on the ECP, and the key to increasing the provincial industrial electricity consumption intensity is to improve the electricity utilization efficiency. $\Delta P_{P R-i}$ shows limited impact on ECP. Overall, the provincial population scale has not yet reached the most conducive to promoting carbon neutrality, so there is still room for improvement.

$\Delta P_{P C}$ is the driver with the greatest negative impact, reflecting the fact that the growth rate of electricity $\mathrm{CO}_{2}$ emissions is significantly higher than the population growth rate. $\Delta P_{E C I-i}$ can manifest the use of electricity in economic activities. From the international aspect, China's electricity consumption intensity is still higher than the major developed countries, which is about 2.9 times that of the United States [40], because the proportion of the tertiary industry and the level of 
Table 3. Contribution rates of each driver for China's ECP from the consumption side.

\begin{tabular}{|c|c|c|c|c|c|c|}
\hline Year & $\Delta P_{R E C I-i j}$ & $\Delta P_{I E C-i j}$ & $\Delta P_{E C I-i}$ & $\Delta P_{P C G-i}$ & $\Delta P_{P R-i}$ & $\Delta P_{P} \mathrm{C}$ \\
\hline $2007-2008$ & 0.6608 & 0.0705 & -0.3238 & 0.4689 & 0.0168 & 0.1069 \\
\hline $2008-2009$ & -0.4121 & -1.0192 & 2.3874 & -7.2380 & -0.5465 & 7.8284 \\
\hline $2009-2010$ & 0.8549 & -0.1305 & -0.5744 & 1.8893 & 0.0937 & -1.1330 \\
\hline $2010-2011$ & 1.1603 & 0.0157 & -1.3339 & 3.5622 & 0.0273 & -2.4317 \\
\hline $2011-2012$ & 0.6125 & 0.0171 & -0.2930 & 0.5894 & 0.0086 & 0.0654 \\
\hline $2012-2013$ & 1.3025 & -0.0599 & -1.2910 & 2.7637 & 0.0302 & -1.7454 \\
\hline $2013-2014$ & 0.6435 & 0.0132 & -0.3001 & 0.5703 & 0.0065 & 0.0666 \\
\hline $2014-2015$ & 0.5672 & 0.1035 & -0.2390 & 0.4301 & 0.0102 & 0.1280 \\
\hline $2015-2016$ & 0.5142 & 0.1516 & -0.1918 & 0.5565 & 0.0032 & -0.0338 \\
\hline $2016-2017$ & 0.5281 & 0.2093 & -0.6742 & 1.9400 & 0.0208 & -1.0240 \\
\hline $2007-2017$ (Average) & 0.6432 & -0.0629 & -0.2834 & 1.2034 & 0.0218 & -0.5530 \\
\hline
\end{tabular}

energy-saving technologies in the United States is higher than that in China. To analyze the reasons for high industrial electricity consumption intensity, on the one hand, some provinces have developed rapidly in high energy-intensive industries, which have a more obvious promotion effect on electricity, but the economic development is out of sync. On the other hand, the growth of non-productive power consumption is faster, such as household power consumption does not directly increase GDP, but only directly waste electricity. In consequence, the improvement of China's electricity utilization efficiency in the future is still a larger space. For the sake of analysis $\Delta P_{I E C-i j}$, Fig. 5 shows the power consumption of three industrial sectors. The secondary industry shows the highest power consumption, of which the high energy-intensive industries have a long-term high proportion in the secondary industry, but the contribution rate of the secondary industry to GDP is declining, from $50.1 \%$ in
2007 to $34.2 \%$ in 2017. With China stepping into the middle and late stage of industrialization, the supporting role of the tertiary industry for economic development has become more and more obvious. The proportion of the tertiary industry is increasing, but it is still lower than the world average. In 2007, the proportion of the tertiary industry in China was $52.68 \%$, and the global average of the proportion of the tertiary industry was $65.9 \%$ [41]. What's more, increasing the proportion of the tertiary industry will reduce electricity consumption intensity, but it will improve energy efficiency. Hence, increasing investment in tertiary industries with low energy consumption and high output, and relatively reducing investment in high energy-intensive secondary industries can promote industrial upgrading and improve the level of ECP.

In Fig. 6, ECP has four periods of distinct changes along the timeline. The change in ECP from 2008 to 2009 was -0.0162 , which was the only period that

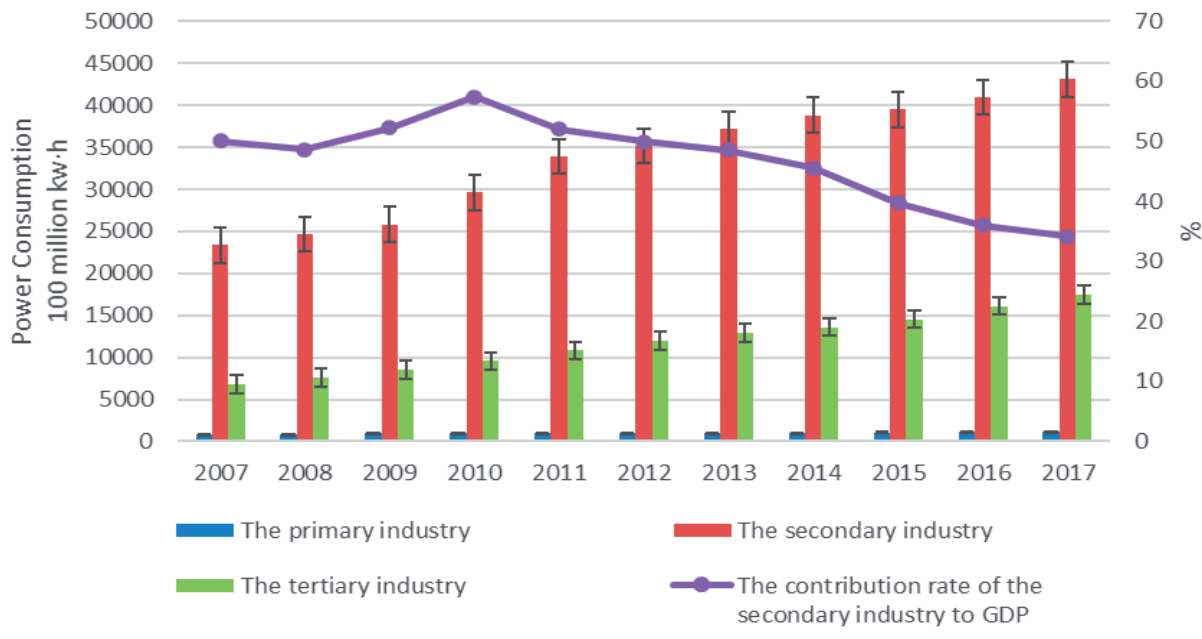

Fig. 5. Power consumption of three industrial sectors in China, 2007-2017. 


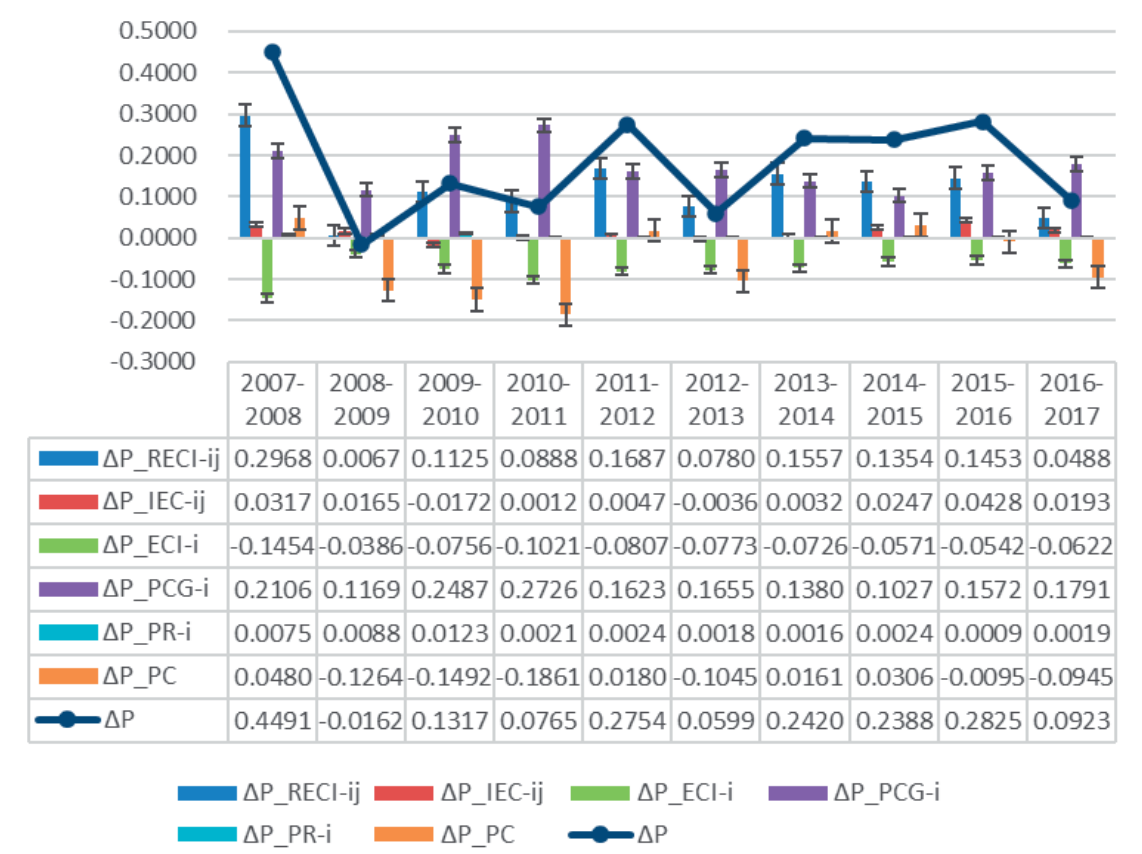

Fig. 6. Effects of drivers for Chinese ECP increment from the consumption side.

Table 4. Drivers for Chinese provincial ECP (100 million Yuan*10-3/ten thousand tonnes) from the consumption side in $2007-2017$.

\begin{tabular}{|c|c|c|c|c|c|c|}
\hline Province & $\Delta P_{R E C I-i j}$ & $\Delta P_{I E C-i j}$ & $\Delta P_{E C I-i}$ & $\Delta P_{P C G-i}$ & $\Delta P_{P R-i}$ & $\Delta P_{P C}$ \\
\hline Beijing & 38.760 & 4.353 & -33.588 & 46.663 & 10.050 & -18.069 \\
\hline Tianjin & 30.989 & 4.629 & -26.859 & 33.018 & 9.845 & -11.909 \\
\hline Hebei & 40.124 & 2.616 & -25.732 & 63.601 & 2.222 & -25.636 \\
\hline Shanxi & 19.104 & 5.600 & -18.127 & 29.357 & 1.035 & -11.391 \\
\hline Inner Mongolia & 19.052 & 1.653 & 5.512 & 34.192 & -0.579 & -14.553 \\
\hline Liaoning & 20.047 & 3.557 & -14.930 & 45.005 & -2.663 & -22.258 \\
\hline Jilin & 20.542 & 1.041 & -20.548 & 33.739 & -2.288 & -11.054 \\
\hline Heilongjiang & 15.637 & 6.469 & -16.307 & 31.015 & -2.408 & -12.857 \\
\hline Shanghai & 63.792 & 6.774 & -35.556 & 48.725 & 5.521 & -22.244 \\
\hline Jiangsu & 136.303 & 28.423 & -85.949 & 192.111 & -2.443 & -53.311 \\
\hline Zhejiang & 69.279 & 11.981 & -38.520 & 99.803 & 4.354 & -34.810 \\
\hline Anhui & 46.356 & 0.175 & -18.590 & 61.581 & -0.776 & -15.816 \\
\hline Fujian & 53.196 & 5.134 & -29.783 & 70.455 & 1.869 & -19.163 \\
\hline Jiangxi & 32.856 & -3.185 & -10.569 & 44.986 & 0.061 & -12.308 \\
\hline Shandong & 99.454 & -1.836 & -30.141 & 146.938 & 2.499 & -49.932 \\
\hline Henan & 64.361 & 10.034 & -51.504 & 96.432 & -2.608 & -29.379 \\
\hline Hubei & 19.637 & -4.181 & -40.926 & 81.996 & -0.792 & -19.847 \\
\hline Hunan & 57.316 & 18.527 & -57.553 & 76.658 & 1.479 & -20.902 \\
\hline Guangdong & 123.073 & 11.624 & -86.635 & 164.878 & 16.629 & -58.549 \\
\hline Guangxi & 28.516 & 3.293 & -15.389 & 41.411 & -0.681 & -12.309 \\
\hline Hainan & 7.495 & 0.675 & -2.212 & 9.826 & 0.418 & -2.682 \\
\hline Chongqing & 40.996 & 0.368 & -20.688 & 43.430 & 1.308 & -10.590 \\
\hline
\end{tabular}


Table 4. Continued.

\begin{tabular}{|c|c|c|c|c|c|c|}
\hline Sichuan & 61.400 & 1.164 & -46.429 & 85.509 & -1.710 & -22.448 \\
\hline Guizhou & 26.616 & 3.640 & -18.002 & 34.042 & -0.887 & -6.500 \\
\hline Yunnan & 26.789 & 2.476 & -17.504 & 36.144 & 0.257 & -9.686 \\
\hline Shannxi & 38.451 & 2.018 & -15.130 & 52.366 & -0.686 & -13.257 \\
\hline Gansu & 9.977 & 0.709 & -6.029 & 15.562 & -0.320 & -5.253 \\
\hline Qinghai & 4.158 & 1.088 & -1.921 & 5.723 & 0.156 & -1.746 \\
\hline Ningxia & 5.988 & 0.775 & -3.012 & 7.757 & 0.421 & -2.190 \\
\hline Xinjiang & 16.324 & -6.261 & 16.802 & 20.724 & 2.495 & -6.922 \\
\hline
\end{tabular}

showed negative value. Affected by the economic crisis, the contribution rate of per capita GDP to ECP reached $-723.8 \%$ (Table 2). Since 2009, ECP increments have been positive. In 2011-2012, the ECP increment reached a high value. As China's residential electricity used step tariff at the end of 2011, rational use of electricity through economic means will help increase ECP values and promote carbon neutrality. From 2013 to 2016, ECP increased year by year, because China promulgated a series of energy conservation, emission reduction and industrial energy price adjustment policies. Especially carbon abatement of thermal power generation, so the transformation of thermal power generation to energy conservation and emission reduction had entered a stage of high-speed and high-quality development. In 2016-2017, the increment in ECP decreased to 0.0923. In 2017, due to the pressure of assessment, the construction of energy-intensive projects increased, resulting in a large increase in the power consumption of the secondary industry.

\section{In-depth Analysis of the Provinces Based on Consumption Side}

Table 4 shows the contribution values of the electricity consumption structure effect of provincial industry $\left(\triangle P_{I E C-i j}\right)$ in Xinjiang, Jiangxi, Hubei, and Shandong are negative, indicating that the proportion of industrial power consumption in the provinces is declining, and the proportion of non-productive power consumption is increasing. The contributions of the provincial electricity consumption intensity effect $\left(\triangle P_{E C L-i}\right)$ in Xinjiang and Inner Mongolia are positive, indicating that the electricity consumption intensity of the two provinces is increasing. For example, Xinjiang has undertaken the transfer of high energy-intensive industries such as electrolytic aluminum, and the electricity utilization efficiency is low. The population scale effect $\left(\Delta P_{P R-i}\right)$ has subtle influence on ECP, which means that the population growth of other provinces except Guangdong, Beijing, Tianjin and Zhejiang is similar to that of the whole country. Specifically, from the regional perspective, the population scale of Guangdong, Beijing, Tianjin, and Zhejiang has a greater impact on ECP than other regions, and these provinces are the main areas of net population inflow. Similarly, regional differences in other parameters are not obvious.

\section{Conclusions}

This study explores the carbon neutrality of the power industry through the study of the ECP in 30 provinces in China during the period 2007-2017, effectively combining the economy and the environment. Based on the LMDI method, the ECP is decomposed on the power production and consumption side, while considering the regional and industrial dimensions. Finally, it is decomposed into six driving factors respectively, and the following main conclusions are drawn:

From the perspective of production, first, the provincial ECP and the reciprocal of standard coal consumption for power supply are the main driving factors for improving China's ECP. Raising regional ECP is the top priority. With regard to reducing coal consumption for power supply, China has listed clean and efficient use of coal as Science and Technology Innovation 2030 Major Project. In addition, the power generation structure, the $\mathrm{CO}_{2}$ emission intensity of power generation and standard coal structure effect are negative factors for ECP growth. In the context of China's announcement that it plans to achieve carbon neutrality by 2060 and peak coal consumption by 2025 , the development of clean energy should be accelerated. Second, in-depth analysis of the provinces, the ECP of each province shows significant regional differences. Xinjiang's ECP level is the lowest because Xinjiang's economic growth relies to a large extent on the support of high investment and high energy-intensive, following an extensive economic development path. Guangdong, Jiangsu and Sichuan have the highest levels of ECP. In Guangdong and Jiangsu, the inflow of electricity has resulted in low local electricity production-based $\mathrm{CO}_{2}$ emissions; in Sichuan, on the one hand, lowcarbon energy reduces local electricity $\mathrm{CO}_{2}$ emissions; on the other hand, as China's economy has entered the 'New Normal' era, the slowdown in economic growth has accelerated the decarbonization of Sichuan's 
power industry. Third, according to the timeline analysis of ECP changes, the continuous growth of ECP from 2007 to 2017 benefited from economic development and optimization of the power generation structure.

From the perspective of consumption, first, the provincial per capita GDP and the reciprocal provincial industrial electricity consumption intensity are the main positive factors for ECP growth. ECP can be enhanced by improving electricity utilization efficiency and economic development, but it is more critical to master the balance between ECP and economic development. If a higher level of ECP is to be achieved, the economy will be sacrificed up to a point. In addition, the $\mathrm{CO}_{2}$ emissions per capita and the provincial electricity consumption intensity are the main negative factors. On the one hand, technological transformation can improve electricity utilization efficiency and realize energy conservation and emission reduction; on the other hand, it can promote industrial upgrading. Second, for in-depth analysis of the provinces, low electricity utilization efficiency is the reason why ECP in Xinjiang, Inner Mongolia and other places is lower than that in Jiangsu and Guangdong. Third, for the analysis of change in the ECP according to the timeline, ECP only declined in 2008-2009 due to the negative impact of the financial crisis.

\section{Acknowledgments}

This research was supported by National Science Foundation of China (72101089).

\section{Conflict of Interest}

The authors declare no conflict of interest.

\section{References}

1. BP. Energy Outlook 2020 edition. Available online: https:// www.bp.com/en/global/corpo-rate/news-and-insights/ press-releases/bp-energy-outlook-2020.html (accessed on 13 February 2021)

2. National Bureau of Statistics. Available online: http:/ www.stats.gov.cn/tjsj/, 2020. (accessed on 13 February 2021).

3. CEC (China Electric Council). China's Electric Power Statistical Yearbook 2020. China's Electric Power Press, Beijing, China, 2019.

4. JIA Z.J., LIN B.Q. How to achieve the first step of the carbon-neutrality 2060 target in China: The coal substitution perspective. Energy, 233, 121179, 2021.

5. CHEN G.J., HOU F.J., CHANG K.L., ZHAI Y.B., DU Y.Q. Driving factors of electric carbon productivity change based on regional and sectoral dimensions in China. Journal of cleaner production, 205, 477, 2018.

6. LI W.W., WANG W.P., WANG Y., ALI M. Historical growth in total factor carbon productivity of the Chinese industry-a comprehensive analysis. Journal of cleaner production, 170, 471, 2018.
7. KAYA Y., YOKOBORI K. Environment, energy and economy: strategies for sustainability. Delhi: Bookwell Publications, 1999.

8. SHAO C.F., GUAN Y., WAN Z., GUO C.X., CHU C.L., JU M.T. Performance and decomposition analyses of carbon emissions from industrial energy consumption in Tianjin, China. Journal of cleaner production, 64, 590, 2014.

9. WANG K., XIAN Y., WEI Y-M., HUANG Z. Sources of carbon productivity change: A decomposition and disaggregation analysis based on global Luenberger productivity indicator and endogenous directional distance function. Ecological Indicators, 66, 545, 2016.

10. MENG M., NIU D., GAO Q. Decomposition Analysis of Chinese Provincial Economic Growth through Carbon Productivity Analysis. Environmental Progress \& Sustainable Energy, 33 (1), 250, 2013.

11. SUN W., HE Y.J., GAO H. An Electric Carbon Productivity Analysis of China's Industrial Sector Using Multi-Dimensional Decomposition. Polish Journal of Environmental Studies, 25 (4), 1699, 2016.

12. HE J., SU M. Carbon Productivity Analysis to Address Global Climate Change. China Soft Science, 9 (1), 42, 2009.

13. YU Y., QIAN T., DU L. Carbon productivity growth, technological innovation, and technology gap change of coal-fired power plants in China. Energy Policy, 109, 479, 2017.

14. YU Y., CHOI Y., WEI X., CHEN Z. Did China's regional transport industry enjoy better carbon productivity under regulations? Journal of cleaner production, 165, 777, 2017.

15. BAI C., DU K., YU Y., FENG C. Understanding the trend of total factor carbon productivity in the world: Insights from convergence analysis. Energy Economics.

16. DING L., YANG Y., WANG W., CALIN A.C. Regional carbon emission efficiency and its dynamic evolution in China: A novel cross efficiency-malmquist productivity index. Journal of Cleaner Production, 241, 118260, 2019.

17. HU W., WANG D. How does environmental regulation influence China's carbon productivity? An empirical analysis based on the spatial spillover effect. Journal of Cleaner Production, 257, 120484, 2020.

18. PAN J., ZHANG L. Research on the regional variation of carbon productivity in China. China Industrial Economics, No. 5, 47, 2011.

19. HU X., LIU C. Carbon productivity: a case study in the Australian construction industry. Journal of Cleaner Production, 112, 2354, 2016.

20. LONG R., SHAO T., CHEN H. Spatial econometric analysis of China's province-level industrial carbon productivity and its influencing factors. Applied Energy, 166, 210, 2016.

21. LI S., WANG S. Examining the effects of socioeconomic development on China's carbon productivity: A panel data analysis. Science of the Total Environment, 659, 681, 2019.

22. YANG H., LU Z., SHI X., MENSAH I.A., LUO Y.S., CHEN W.J. Multi-region and multi-sector comparisons and analysis of industrial carbon productivity in China. Journal of Cleaner Production, 279, 123623, 2021.

23. ZHANG L., XIONG L., CHENG B., YU C. How does foreign trade influence China's carbon productivity? Based on panel spatial lag model analysis. Structural Change and Economic Dynamics, 47, 171, 2018.

24. DU K., LI J. Towards a green world: How do green technology innovations affect total factor carbon productivity. Energy Policy, 131, 240, 2019. 
25. PAN X., LI M., WANG M., CHU J., BO H. The effects of outward foreign direct investment and reverse technology spillover on China's carbon productivity. Energy Policy, 145, 111730, 2020.

26. LONG R., GAN X., CHEN H., WANG J., LI Q. Spatial econometric analysis of foreign direct investment and carbon productivity in China: Two-tier moderating roles of industrialization development. Resources, Conservation \& Recycling, 155, 104677, 2020.

27. FAN L.-W. YOU J.M., ZHANG W., ZHOU P. How does technological progress promote carbon productivity? Evidence from Chinese manufacturing industries. Journal of Environmental Management, 277, 111325, 2021.

28. TAN Z., LI L., WANG J.J. Examining the driving forces for improving China's $\mathrm{CO}_{2}$ emission intensity using the decomposing method. Applied Energy, 88 (12), 4496, 2011.

29. ANG B.W. The LMDI approach to decomposition analysis: a practical guide. Energy policy, 33, 867, 2005.

30. VARTIA Y. Relative changes and economic indices. (A Licenciate Thesis, in Finnish.) University of Helsinki, Department of Statistics, 1974.

31. SATO K. The ideal log-change index number. The Review of Economics and Statistics, 58 (2), 223, 1976.

32. VARTIA. Ideal log-change index numbers. Scandinavian Journal of Statistics. 3 (3), 121, 1976.

33. CEPY. China Electric Power Yearbook 2007-2017. China Electricity Yearbook Editorial Board, China Electric Power Press, Beijing.

34. CESY. China Energy Statistical Yearbook 2007-2017. Department of Energy Statistics, National Bureau of Statistics, China Statistics Press, Beijing.

35. SUN X.D., ZHANG B., PENG S.P. Development Trend and Strategic Countermeasures of Clean Coal Technology in China Toward 2035. Strategic Study of CAE, 22 (3). 132, 2020.

36. YAO X.L., LEI H.T., YANG L.L. SHAO S., AHMED D., ISMAAIL M.G.A. Low-carbon transformation of the regional electric power supply structure in China: A scenario analysis based on a bottom-up model with resource endowment constraints. Resources, Conservation \& Recycling, 167,105315, 2021.

37. XIAN Y.J., WANG K., SHI X.P. ZHANG C., WEI Y-M., HUANG Z.M. Carbon emissions intensity reduction target for China's power industry: An efficiency and productivity perspective. Journal of Cleaner Production, 197, 1022, 2018.

38. WANG S., JIANG H.Y., SUN X., L., ZUO Y., WU P.S, Analysis \& suggestion on shutting down capacity and energy-saving about thermal power units from the view of region in $11^{\text {th }}$ Five years in China. Energy Conservation Technology, 28(163), 446, 2010.

39. ZHANG D.Y., WANG H. ANDREAS L., ZHOU P. The changing role of global value chains in $\mathrm{CO}_{2}$ emission intensity in 2000-2014. Energy Economics, 93, 105053, 2021.

40. XUE W.L., TANG W., XU N., ZHAO X., LI C.H., SHAN B.G., JI X.P. Analysis of current situation of energy and electricity consumption and prediction of energy efficiency development during the $14^{\text {th }}$ five-year plan. Power Demand Side Management, 22 (6), 2020.

41. The added value of the service industry in the world as a percentage of GDP in 2017. Ava-ilable online: https://www. $\mathrm{kylc.com} / \mathrm{stats} / \mathrm{global} / \mathrm{yearly} / \mathrm{g}$ _service_value_added_in gdp/2017.html (accessed on 29 July 2021). 81 698, $201 \overline{9}$. 